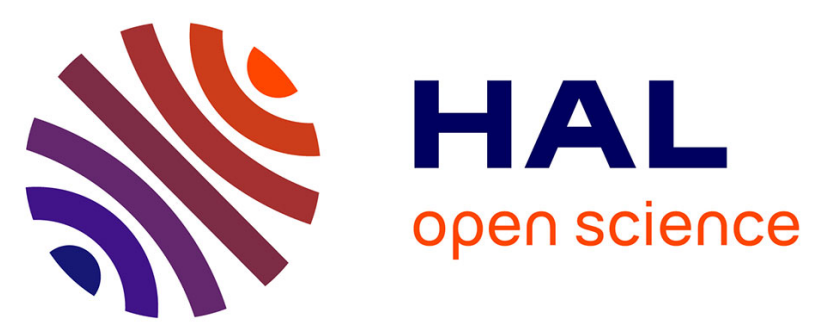

\title{
Fluid dynamics thermo-mechanical simulation of sintering: Uniformity of temperature and density distributions
}

\author{
Charles Manière, Tony Zahrah, Eugene A. Olevsky
}

\section{To cite this version:}

Charles Manière, Tony Zahrah, Eugene A. Olevsky. Fluid dynamics thermo-mechanical simulation of sintering: Uniformity of temperature and density distributions. Applied Thermal Engineering, 2017, 123, pp.603-613. 10.1016/j.applthermaleng.2017.05.116 . hal-02616826

\section{HAL Id: hal-02616826}

https://hal-normandie-univ.archives-ouvertes.fr/hal-02616826

Submitted on 20 Nov 2020

HAL is a multi-disciplinary open access archive for the deposit and dissemination of scientific research documents, whether they are published or not. The documents may come from teaching and research institutions in France or abroad, or from public or private research centers.
L'archive ouverte pluridisciplinaire HAL, est destinée au dépôt et à la diffusion de documents scientifiques de niveau recherche, publiés ou non, émanant des établissements d'enseignement et de recherche français ou étrangers, des laboratoires publics ou privés. 


\title{
Fluid Dynamics Thermo-Mechanical Simulation of Sintering: Uniformity of Temperature and Density Distributions
}

\author{
Charles Manière ${ }^{\mathrm{a}}$, Tony Zahrah ${ }^{\mathrm{b}}$, Eugene A. Olevsky ${ }^{\mathrm{a}, \mathrm{c} *}$
}

(a) Powder Technology Laboratory, San Diego State University, San Diego, USA

(b) Matsys Inc., Sterling, USA

(c) NanoEngineering, University of California, San Diego, La Jolla, USA

Keywords: Sintering; simulation; computational fluid dynamics; densification; complex shape

Graphical Abstract

Fluid Dynamics Thermo-Mechanical Simulation Muffle furnace heating

Densification
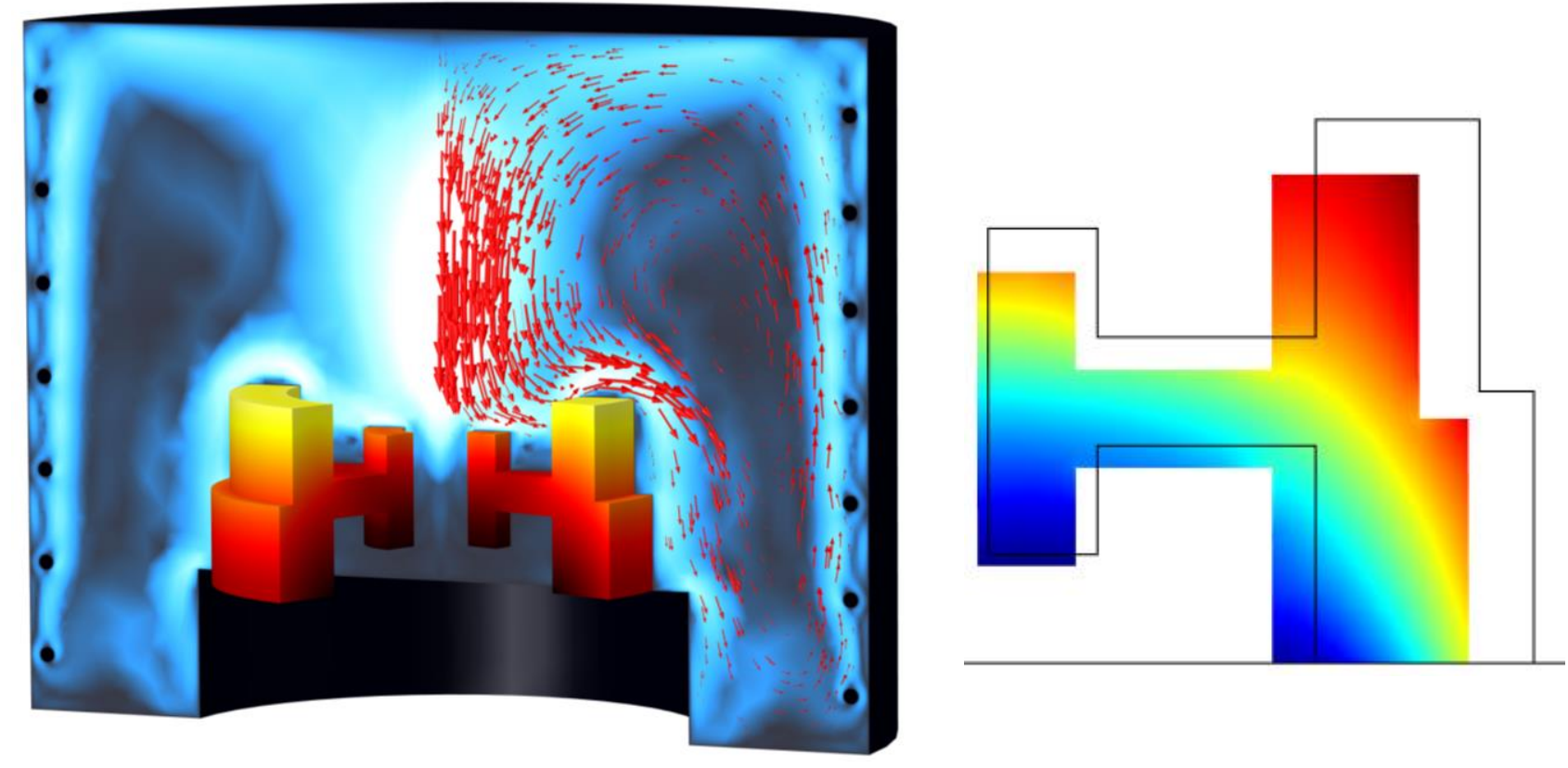

Abstract: One of the main contemporary challenges of sintering simulations is taking into account all the coupled physics present in the sintering process. The model should predict the convection, surface to surface radiation, conduction, specimen sintering phenomena, and also the proportional integral derivative regulation. A fluid dynamics thermo-mechanical model (FDTM) is implemented to predict the degree of uniformity of heating and compaction of a large size gear shape specimens under various process conditions. The FDTM model is validated by a dilatometer test indicating a very good agreement with the experimental data. The complex shape sintering simulation shows that the temperature and densification gradients depend strongly on the sample thickness. A large volume of material can be easily heated if the specimen's shape allows the hot gas to make its way inside the sample volume. If this condition is not satisfied, it is shown that a large and closed volume of material can generate significant temperature and density gradients.

REF: C. Manière, T. Zahrah, E.A. Olevsky, Fluid Dynamics Thermo-Mechanical Simulation of Sintering: Uniformity of Temperature and Density Distributions, Applied Thermal Engineering. (2017). doi:10.1016/j.applthermaleng.2017.05.116. 


\section{Nomenclature}

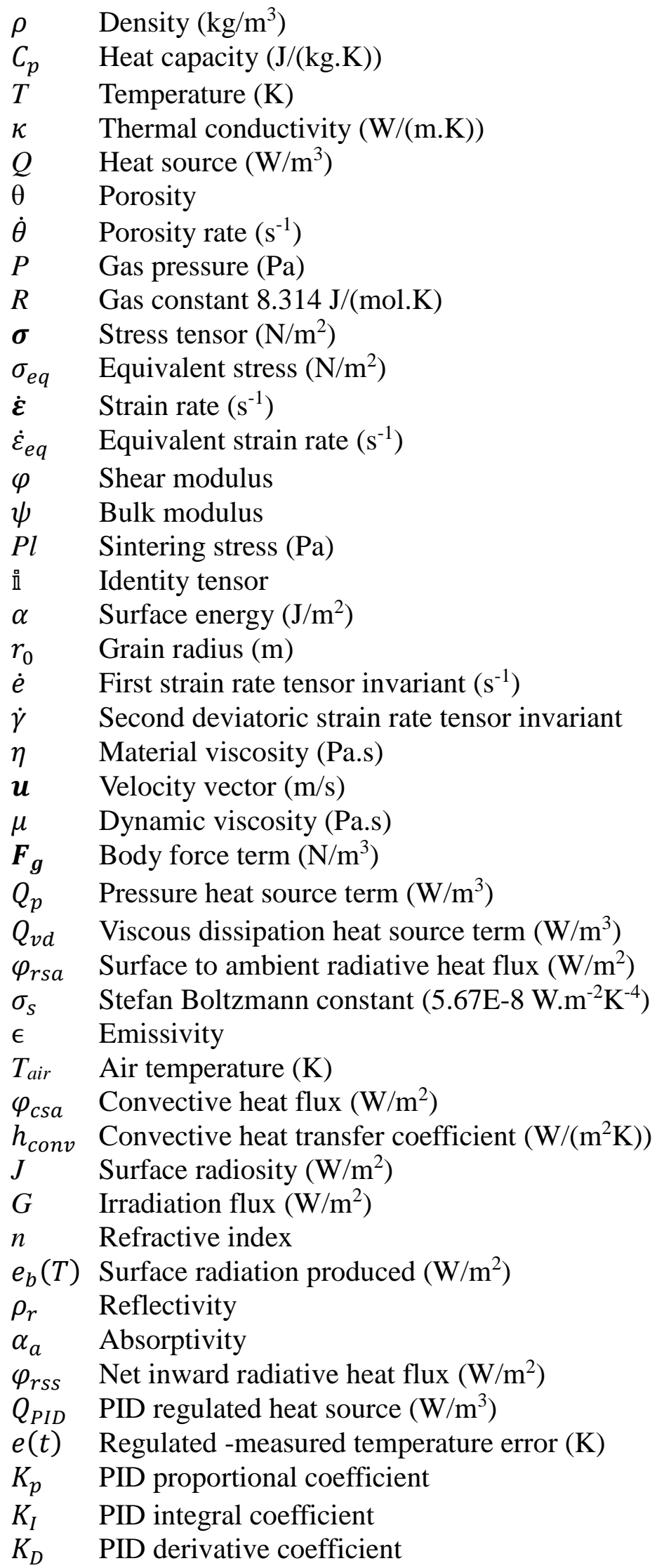




\section{Introduction}

Conventional sintering is the oldest and the most currently employed sintering method [1-2]. This process implies a consolidation of a powder into a solid material by bounding interconnected particles to each other [3]. This usually requires a thermal treatment performed in a furnace. During this treatment, the heat is generated by a source that can be combustion [4] or high temperature resistive heating elements such as $\mathrm{MoSi}_{2}, \mathrm{FeCrAl}$, graphite, $\mathrm{W}$ [5-6], etc. Heat is then transmitted to the sample by thermal radiation, conduction and convection [7]. The surface-to-surface radiation is mainly governed by the material emissivity that depends on the material chemical composition and the temperature. The thermal conduction has most of the time a very low contribution to heat transfer compared to the convection phenomena because the thermal conductivity of the gas like air or argon is very low [8]. Egorov et al. [9] showed that the heat removal from a sample heated by microwaves is very high when the convection phenomenon is taken into account compared to the pure conduction case where the heat is slowly radially dissipated. The computational fluid dynamics (CFD) part of a conventional sintering furnace model is then a crucial point [10-16].

Nieckele et al. [17] employed a finite volume model for the analysis of the heat transfer inside an industrial aluminum melting furnace. In this study, different configurations of a burner jet (single burner, parallel jet, divergent jet) were compared in order to find the optimal heating configuration that minimized the refractory walls' damage and provided a homogeneous heating. Similarly, Hachem et al. [18-19] presented a turbulent model for the simulation of the heating of a complex industrial combustion furnace. This model based on the immersed volume method [20] showed the capability to predict the heating inhomogeneity in a large size furnace. These types of simulations are powerful tools for the optimization of sintering conditions such as the sample's location, the effect of the sample and furnace shape complexity, the dimensions' effects and the optimization of the energy consumption [21]. However, these models often focus on the fluid dynamics and thermal aspects of the phenomena involved in the furnace heating. The impact of the calculated temperature gradients on the sample sintering and the distortions they generate are usually not considered. 
The aim of this paper is to establish, on the one hand, a multiphysics analysis of a muffle furnace able to predict all the heat transfer phenomena (conduction, convection, surface to surface radiation) and the sintering of a powder sample. The developed model was validated experimentally using a dilatometer furnace. On the other hand, different complex gear sample shapes and large sample dimensions were investigated by the simulations in order to determine the main conditions promoting temperature and densification inhomogeneity. The developed fluid dynamic thermomechanical FDTM model's aim is to be a simulation tool applicable to a wide variety of conventional sintering techniques including all the main physics involved. This model can also be used as a good basis for special sintering technologies such as microwave sintering, where the temperature gradients generated are very sensible $[9,22]$ and require comprehensive multiphysics models to analyze them.

\section{Fluid dynamics thermo-mechanical model}

The FDTM model is based on the Navier-Stokes equations to describe the conductionconvective heat transfer in the gas area taking into account also the contribution of the surface-tosurface radiation. A classical heat transfer model is also employed for the solid parts where for the porous sample volume a sintering model based on the continuum theory of sintering [3] is coupled with the other heat transfers physics. The governing equations of the FDTM model implemented in the commercial finite element software "Comsol Multiphysics" are detailed in the sections 2.1 and 2.2. The boundary conditions and the PID regulation are detailed in sections 2.3 and 2.4 respectively. Section 2.5 is dedicated to the description of each of the sintering configurations explored and to our study strategy. In all the used equations, tensors and vectors are represented in a bold font style and their components in a normal font style.

\subsection{Heat transfer and sintering of the solid parts}

Heat transfer for the solid parts is classically described by the equation:

$$
\rho C_{p} \frac{\partial T}{\partial t}+\nabla(-\kappa \nabla \mathrm{T})=Q
$$


In the porous sample volume, an additional phenomenon is taking place. It is the pressureless sintering. This phenomenon is also included in the FDTM via the continuum theory of sintering equations $[3,23]$ with:

the local equilibrium equation:

$\nabla \cdot \sigma=0$

the strain rate - stress law describing the porous material behavior:

$$
\boldsymbol{\sigma}=\frac{\sigma_{e q}}{\dot{\varepsilon}_{e q}}\left(\varphi \dot{\boldsymbol{\varepsilon}}+\left(\psi-\frac{1}{3} \varphi\right) \operatorname{tr}(\dot{\boldsymbol{\varepsilon}}) \mathfrak{\mathbb { 1 }}\right)+P_{l} \mathbb{\mathbb { 1 }}
$$

with the shear and bulk moduli and the sintering stress expressions [3, 24]:

$$
\begin{aligned}
& \varphi=(1-\theta)^{2} \\
& \psi=\frac{2(1-\theta)^{3}}{3 \theta} \\
& P l=\frac{3 \alpha}{r_{0}}(1-\theta)^{2}
\end{aligned}
$$

The equivalent strain rate and the strain rate tensor invariants are defined by:

$$
\dot{\varepsilon}_{e q}=\frac{1}{\sqrt{1-\theta}} \sqrt{\varphi \dot{\gamma}^{2}+\psi \dot{e}^{2}}
$$

with the strain rate tensor invariants expression:

$$
\begin{aligned}
& \dot{e}=\dot{\varepsilon}_{x}+\dot{\varepsilon}_{y}+\dot{\varepsilon}_{z} \\
& \dot{\gamma}=\sqrt{2\left(\dot{\varepsilon}_{x y}^{2}+\dot{\varepsilon}_{x z}^{2}+\dot{\varepsilon}_{y z}^{2}\right)+\frac{2}{3}\left(\dot{\varepsilon}_{x}^{2}+\dot{\varepsilon}_{y}^{2}+\dot{\varepsilon}_{z}^{2}\right)-\frac{2}{3}\left(\dot{\varepsilon}_{x} \dot{\varepsilon}_{y}+\dot{\varepsilon}_{x} \dot{\varepsilon}_{z}+\dot{\varepsilon}_{y} \dot{\varepsilon}_{z}\right)}
\end{aligned}
$$

The equivalent strain rate - stress behavior can be non-linear when a high external pressure is applied [25] and can be described by a Norton law. For pressureless sintering of powders, the material behavior is most of the time linear [3], the only exception is for the nanometric powder that can generate high sintering stress and, in turn, the non-linearity of the constitutive behavior [26]. In our case, we assume that the powder is not nanometric and a regular linear viscous behavior dominates:

$$
\frac{\sigma_{e q}}{\dot{\varepsilon}_{e q}}=2 \eta(T)
$$


The volume change and porosity evolution are related to each other by the mass conservation equation:

$$
\frac{\dot{\theta}}{(1-\theta)}=\dot{\varepsilon}_{x}+\dot{\varepsilon}_{y}+\dot{\varepsilon}_{z}
$$

\subsection{Heat transfer in the areas occupied by gas}

The fluid dynamics modelling of the furnace in the gas area is a central point for the accuracy of the conventional sintering modeling. Indeed, the convection phenomena significantly accelerate the heat transfer in the furnace with a potential non-homogeneous distribution of the temperature. The Navier-Stokes convective problem is defined by the three main governing equations $[15,20]$ : the mass conservation equation:

$\frac{\partial \rho}{\partial \mathrm{t}}+\nabla \cdot(\rho \boldsymbol{u})=0$

the momentum equation taking into account pressure, viscous response and body forces:

$\rho \frac{\partial \mathbf{u}}{\partial \mathrm{t}}+\rho \boldsymbol{u} \nabla \boldsymbol{u}=-\nabla p+\nabla \cdot\left(\mu\left(\nabla \mathbf{u}+(\nabla \mathbf{u})^{T}\right)-\frac{2}{3} \mu(\nabla \cdot \mathbf{u}) \stackrel{\mathrm{g}}{\mathrm{l}}\right)+\boldsymbol{F}_{\boldsymbol{g}}$

the energy balance equation:

$\rho C_{p}\left(\frac{\partial T}{\partial t}+(\boldsymbol{u} . \nabla) T\right)+\nabla(-\kappa \nabla T)=Q+Q_{p}+Q_{v d}$

The main difference of Eq. (14) compared to the heat equation in solid (1) is the convective term $(\boldsymbol{u} . \nabla) T$ and in the second member, the pressure work $Q_{p}$ and viscous dissipation $Q_{v d}$ heat source terms that are commonly very low for this kind of an application and therefore neglected.

\subsection{Boundary/interface conditions}

The external boundary insulation/air is subjected to a surface to ambient thermal radiation and a convective flux loss (see fig. 1 b) that can be described by the equations:

$$
\begin{aligned}
& \varphi_{r s a}=\sigma_{s} \epsilon\left(T_{a i r}^{4}-T^{4}\right) \\
& \varphi_{c s a}=h_{c o n v}\left(T_{a i r}-T\right)
\end{aligned}
$$



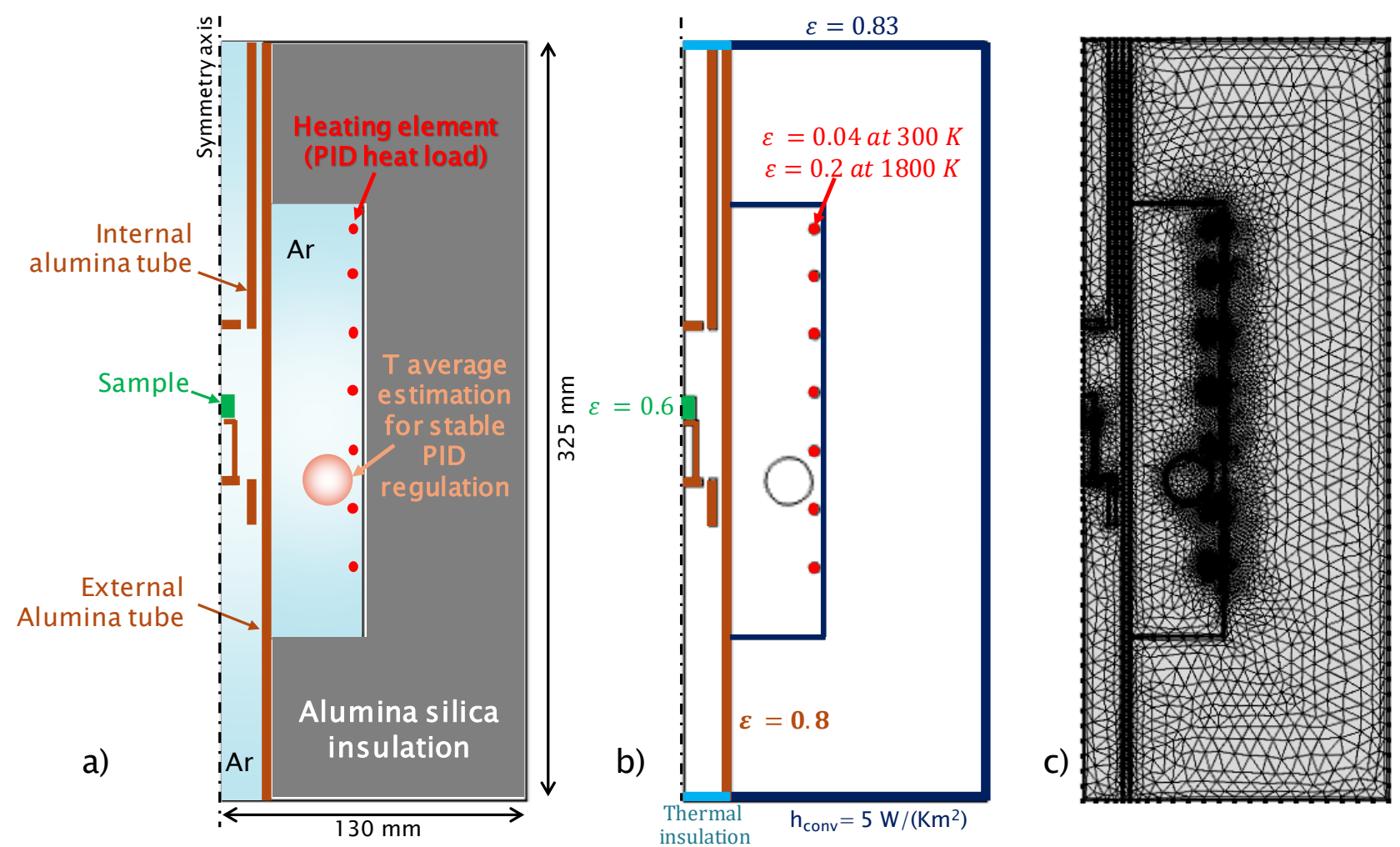

Fig.1 Dilatometer model description, a) configuration, b) boundary condition c) mesh.

The internal solid/argon interfaces are subjected to the mutual surface-to-surface radiation and the fluid dynamics part uses standard "wall" no penetration conditions. The surface-to-surface radiation assumes that the solid body is opaque (no radiation transmitted through the body) and the gas is transparent. The total outgoing radiative flux called radiosity $J$ is defined with the incoming irradiation $\mathrm{G}$ and the power radiated $e_{b}(T)$ :

$$
J=\rho_{r} G+\epsilon e_{b}(T)=\rho_{r} G+\epsilon n^{2} \sigma_{s} T^{4}
$$

with the simplification of ideal gray body:

$$
\alpha_{a}=\epsilon=1-\rho_{r}
$$

the net inward radiative heat flux expression $\varphi_{r s s}$ is:

$$
\varphi_{r s s}=\epsilon\left(G-e_{b}(T)\right)
$$

The mechanical part of the simulation is associated only with the powder sample where for the two points the displacement (along the specimen height axis) is fixed ( $\mathrm{w}=0)$ to ensure an equivalent to the no penetration condition in the support and an unrestricted volume deformation. 


\subsection{Proportional integral derivative temperature regulation}

The $2 \mathrm{~mm}$ diameter heating element is small enough to neglect the current density gradient in it and then the regulation is made not on the current but directly on a homogeneous heat source in the wire. The proportional integral derivative (PID) regulation defines in our case a variable heat source term associated with the resistive heating elements that regulate the furnace temperature. The heat source term $Q_{P I D}$ is [27]:

$$
Q_{P I D}=K_{p} e(t)+K_{I} \int_{0}^{t} e(t) d \tau+K_{D} \frac{d e(t)}{d t}
$$

where $e(t)$ represents the temperature difference between the prescribed set temperature $T_{\text {set }}$ and the furnace temperature simulated $T_{\text {furnace }}$. The tuning of the PID coefficients $K_{p}, K_{I}, K_{D}$ allow the control of the quality of the temperature regulation. However, because the heat flow resulting from the convection in the furnace can be unstable, an estimation of the average furnace temperature in done within a $20 \mathrm{~mm}$ diameter circle (see fig.1). This allows the stabilization of the PID regulation and, at the same time, the estimation of a more representative furnace temperature. In these conditions, the following PID coefficients: $K_{p}=400, K_{I}=20, K_{D}=1000$ provide a good regulation quality.

\subsection{Process modes, simulation strategy, and material properties}

All the process modes investigated in this paper are reported in fig. 2 . The first mode (fig. 1 and fig. 2a) corresponds to a dilatometer (Unitherm model 1161) experiment performed on a $10 \mathrm{~mm}$ diameter and $10 \mathrm{~mm}$ height Ti-6Al-4V sample. This first example is employed to validate our FDTM model in a real case where the sintering shrinkage and the temperature are recorded in two points. In the configurations reported in fig. 2 b. 2 c. 2 d, the FDTM model is employed to simulate the temperature convection and densification efficiency in the different large and complex shape specimens. A $120 \mathrm{~mm}$ gear shape is studied in the configuration reported in fig. $2 \mathrm{~b}$. This complex shape case helps us understand how efficient the convection heating is when the gas path has a complex tortuosity. Indeed, the hot gas has to penetrate through the small $20 \mathrm{~mm}$ diameter gear 
central hole to heat the internal gear boundary. This tortuosity is increased in the configuration shown in fig. $2 \mathrm{c}$ where a second gear shape is placed on the top of the first one with a small $4 \mathrm{~mm}$ aperture to allow the gas to penetrate into the internal area of the bottom gear. The last configuration is a big closed volume of the powder material where the hot gas cannot penetrate in the internal area of the sample.
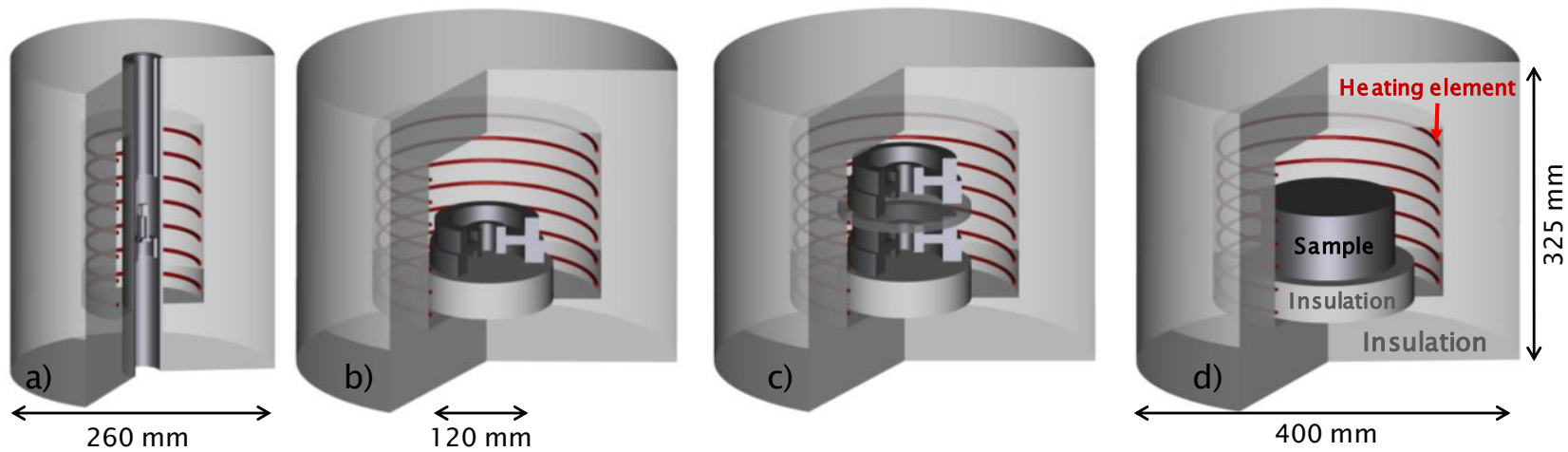

Fig.2 Four configurations: a) dilatometer validation test, b) gear shape, c) two gear configuration, d) large cylinder configuration.

In all these modes/configurations, an alumina-silica fibrous material $\left(80 \% \mathrm{Al}_{2} \mathrm{O}_{3}-20 \% \mathrm{SiO}_{2}\right)$ is employed for the insulation materials. For the dilatometer sintering case, the central insulation tubes are made from the fully dense alumina. The samples' material is Ti-6Al-4V with an initial relative density of 0.66 ; the Ti-6Al-4V powder consists of $50 \mu \mathrm{m}$ agglomerated particles. The chamber is filled with argon in order to prevent the oxidation of the Ti-6Al-4V samples. All the temperature dependent material properties employed in the simulations are reported in Table. 1. All the simulations and the dilatometry are considered to temperatures far below the Ti-6Al-4V melting point of $1878 \mathrm{~K}$. This prevent dealing with special high temperature phenomena such as local melting or the gravity distortions that can happen when the temperature is very closed to the melting point.

In order to improve the calculation time for this comprehensive multiphysics model, an axisymmetric analysis is employed. This approximation is applicable to the utilized dilatometer geometry where all the parts are concentric cylindrical shapes. Concerning the gear shape, only the details at the teeth shapes of the gear are not represented because of this axisymmetric 
approximation. The model thereby focuses on the impact of the general shape of the gear on the physical parameters' spatial distributions. With this approximation, the calculation duration is about 10 hours.

\section{Results and discussion}

\subsection{Dilatometer simulation/experiment results}

During the dilatometer experiment the temperature was recorded at the sample and in the furnace. The sample shrinkage was also recorded allowing the determination of the sample densification curve. This experiment enables the study of the heat transfer and of the mechanical aspects of the FDTM simulation at the same time. In the FDTM model, a heat source added to the heating elements is used to control the furnace temperature by a PID formula. The initial moments of the heating are reported in fig.3. As expected the heating elements start to heat first (fig.3a), then the gas density decreases with the temperature (see Table 1) and the hot gas area starts to move up. The convection phenomenon starts. Because the heating elements are located at the furnace inner lateral boundary, a circular convection motion is observed (fig.3b). During the heating cycle, the distribution of the temperature (fig.4) shows a lag of the central tube heating. The heating in the furnace area is quickly homogenized by the convection phenomenon, but the heating of the central tube area is limited by the thermal conduction across the alumina tube thickness. This configuration is employed to easily control the powder sample area atmosphere but it results in a heating lag of the sample that is significantly reduced at about $900 \mathrm{~K}$ (fig.5a), - a temperature where the sintering shrinkage of the sample starts (fig.5b). The convection phenomena in the central tube are not significant because the related space is very narrow and, for the same reason, the temperature distribution is very homogeneous. 


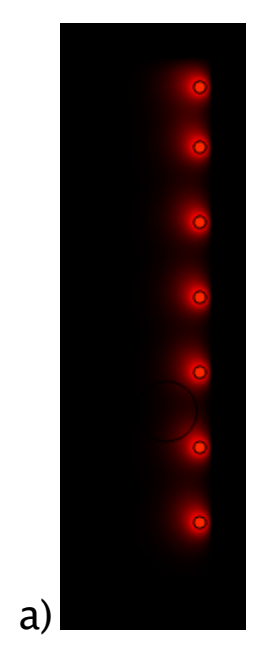

$2 \mathrm{~s}$

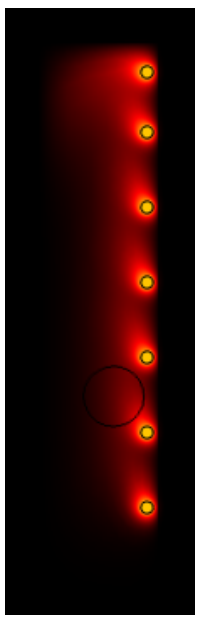

$5 \mathrm{~s}$

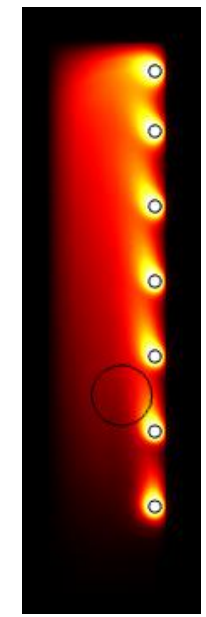

$10 \mathrm{~s}$

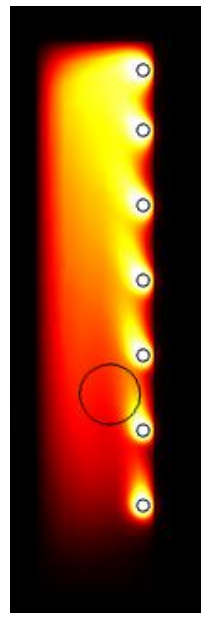

$15 \mathrm{~s}$

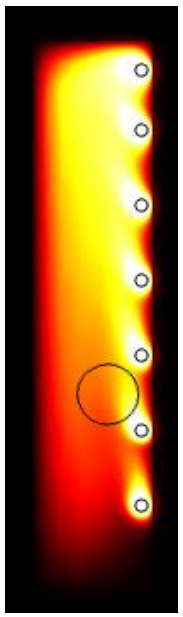

$20 \mathrm{~s}$

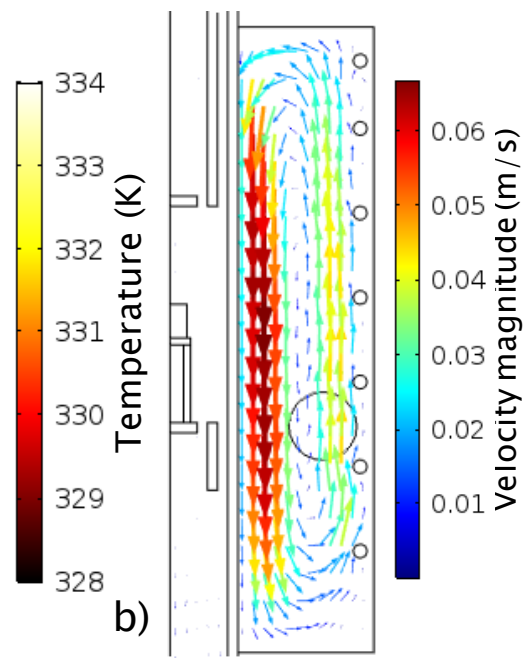

Fig.3 Dilatometer initial heating, a) temperature, b) convection velocity field.

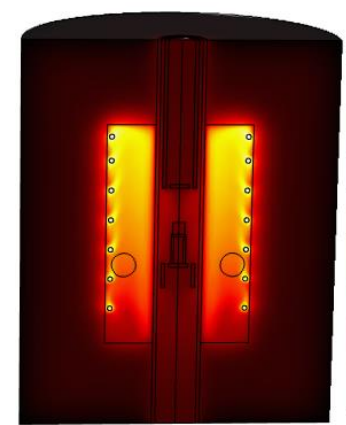

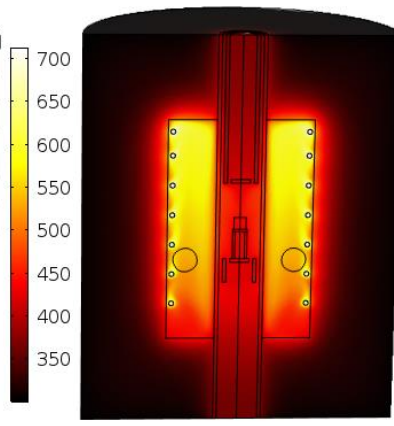

$2000 \mathrm{~s}$

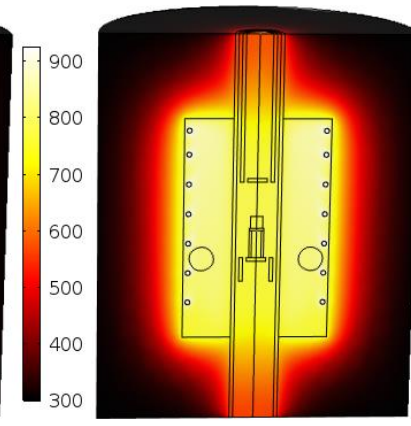

$5000 \mathrm{~s}$

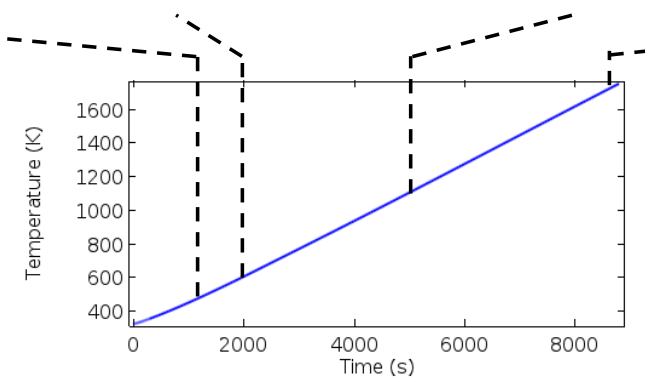

Fig.4 Dilatometer temperature distribution.

The simulated and experimental temperature curves and the sintering densification curves show a very good agreement (fig.5). The heating lag of the sample is well reproduced by the FDTM model for the similar temperature values. The next sections are devoted to the analysis of the powder sample shape impact on the temperature and densification homogeneity by the FDTM simulation approach. 


\begin{tabular}{|c|c|c|c|c|}
\hline & $\begin{array}{c}80 \% \mathrm{Al}_{2} \mathrm{O}_{3-} \\
20 \% \mathrm{SiO}_{2}[28]\end{array}$ & $\mathrm{Al}_{2} \mathrm{O}_{3}$ [29] & Ti-6Al-4V [25] & Argon [30] \\
\hline $\begin{array}{l}\text { Thermal } \\
\text { conductivity } \\
(\mathrm{W} /(\mathrm{m} . \mathrm{K}))\end{array}$ & $1.40 \mathrm{E}-4 \mathrm{~T}+1.70 \mathrm{E}-2$ & $39500 \mathrm{~T}^{-1.26}$ & $\begin{array}{c}(8.11- \\
0.0149 \mathrm{~T}+4.47 \mathrm{E}-5 \mathrm{~T}^{2}- \\
\left.2.27 \mathrm{E}-8 \mathrm{~T}^{3}\right) \times(1-(3 / 2) \\
\theta)\end{array}$ & $\begin{array}{c}\mathbf{3 0 0 - 6 9 0 K} \\
-2.47 \mathrm{E}-4+7.37 \mathrm{E}-5 \mathrm{~T}- \\
5.23 \mathrm{E}-8 \mathrm{~T}^{2}+2.30 \mathrm{E}- \\
11 \mathrm{~T}^{3} \\
\mathbf{6 9 0 - 2 0 0 0 K} \\
0.00422+5.58 \mathrm{E}-5 \mathrm{~T}- \\
2.63 \mathrm{E}-8 \mathrm{~T}^{2}+1.05 \mathrm{E}- \\
11 \mathrm{~T}^{3}-1.59 \mathrm{E}-15 \mathrm{~T}^{4}\end{array}$ \\
\hline $\begin{array}{l}\text { Heat capacity } \\
(\mathrm{J} /(\mathrm{kg} \cdot \mathrm{K}))\end{array}$ & $\begin{array}{c}-5.31 \mathrm{E}- \\
4 \mathrm{~T}^{2}+1.25 \mathrm{~T}+5.18 \mathrm{E} 2\end{array}$ & 850 & $\begin{array}{c}(383+0.671 \mathrm{~T}-5.35 \mathrm{E}- \\
\left.4 \mathrm{~T}^{2}+1.64 \mathrm{E}-7 \mathrm{~T}^{3}\right) \times \\
(1-\theta)\end{array}$ & 520 \\
\hline Density $\left(\mathrm{kg} / \mathrm{m}^{3}\right)$ & $-1.04 \mathrm{E}-2 \mathrm{~T}+4.43 \mathrm{E} 2$ & 3899 & $\begin{array}{c}(4467-0.119 \mathrm{~T}-1.28 \mathrm{E}- \\
\left.5 \mathrm{~T}^{2}\right) \times(1-\theta)\end{array}$ & $0.03994 \mathrm{P} /(\mathrm{RT})$ \\
\hline $\begin{array}{l}\text { Dynamic viscosity } \\
\text { (Pa.s) }\end{array}$ & - & - & - & $\begin{array}{c}2.82 \mathrm{E}-6+7.51 \mathrm{E}-8 \mathrm{~T}- \\
3.01 \mathrm{E}-11 \mathrm{~T}^{2}+8.88 \mathrm{E}- \\
1 \mathrm{~T}^{3}-1.01 \mathrm{E}-18 \mathrm{~T}^{4}\end{array}$ \\
\hline
\end{tabular}

Table. 1: $\quad$ Materials properties, where $\mathrm{T}, \theta, \mathrm{P}, \mathrm{R}$ are the temperature (K), porosity, pressure $(\mathrm{Pa})$ and gas constant $(8.314 \mathrm{~J} /(\mathrm{mol} . \mathrm{K}))$, respectively.
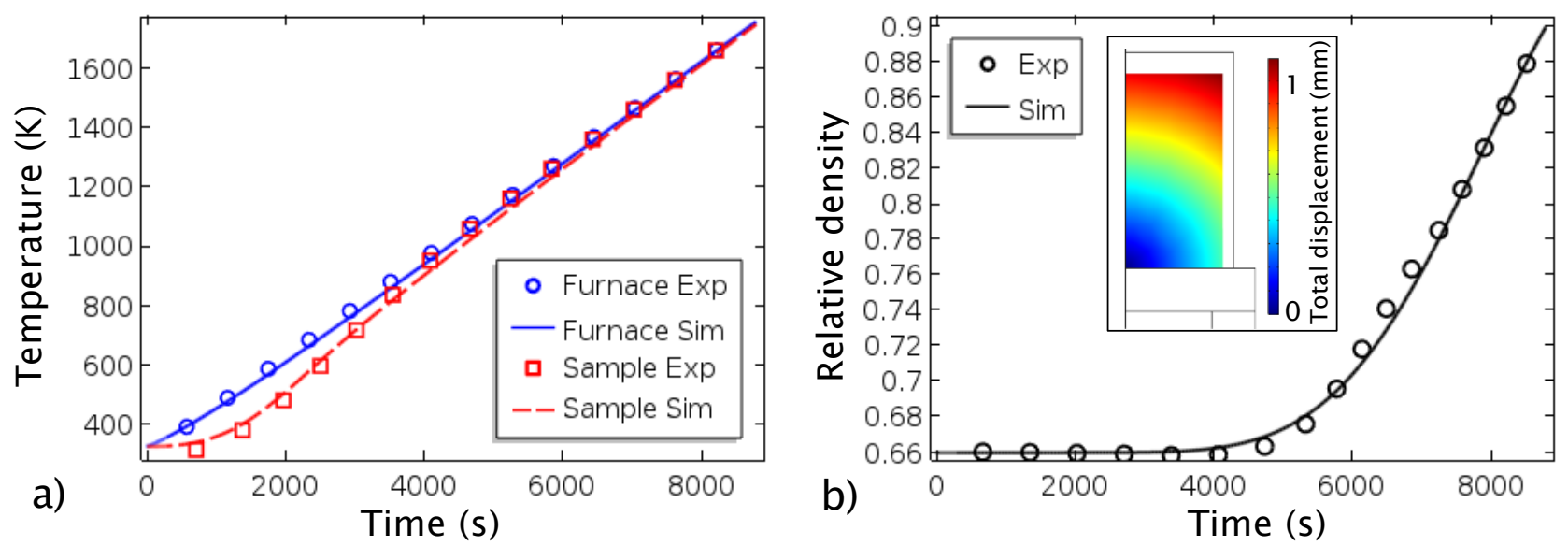

Fig.5 Simulation/experiment comparison, a) furnace/sample temperature curves, b) sample relative density evolution.

\subsection{Convection in the large size sample configurations}

The velocity field distribution resulting from the convection phenomena in the large size powder sample simulations are reported in fig.6. Similarly to the dilatometer case, a circular gas motion is observed. The gas moves up in the area closed to the heating elements and moves down in the central areas. Because of the circular geometry, all the rising gas flow generated in the heating area (on the edge) is concentrated in the central area having a reduced volume. The downward central flow is therefore of a higher magnitude. This geometrical influence on the velocity field magnitude can be clearly seen for the first gear configuration (fig.6a) where the central furnace area is mainly empty. In the other configurations (fig.6b. 6c) this central area is occupied by the powder sample 
volume that decreases the downward flow magnitude compared to the first gear case (fig.6a). Another noticeable point is the velocity field magnitude in the internal gear area (fig.6b. 6c). These areas have a narrow inlet and almost no outlet path, the gas motion in these areas is then limited to a very slow circular flow.
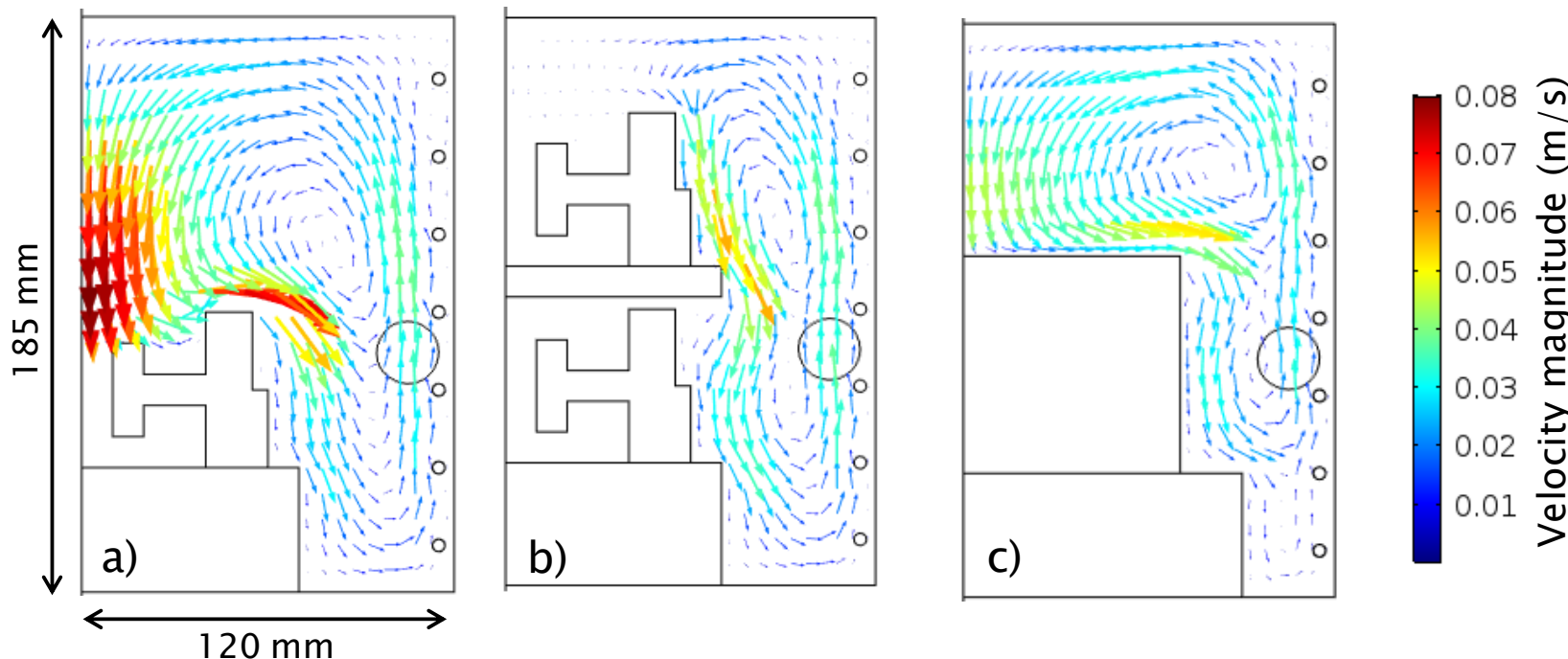

Fig.6 Convective velocity distribution for the a) gear, b) two gears and c) cylinder configurations.

\subsection{The gear shape configurations}

The overall temperature distribution of the first gear shape configuration is reported in fig.7. Two main stages of the furnace heating are thus revealed. During the first stage, the main argon area heat fast while the heating of the sample (including the argon volume inside the sample) is in lag. During the heating ramp, between $2000-5000 \mathrm{~s}$, the transition to a second stage of the heating occurs where all the main furnace area including the sample's volume is homogeneously heated. During this second stage, the only gradient remaining is located at the thermal insulation where the external boundary remains at a low temperature. The relative density and temperature fields in the sample during sintering $(8000 \mathrm{~s})$ are reported in fig.8. The relative density curves show that the sintering shrinkage of the sample starts during the second heating stage when the temperature field is homogeneous. Consequently, the temperature and densification fields in the sample are very homogeneous with temperature differences of $20 \mathrm{~K}$ and densification differences of $1 \%$. The sample shape manifests no distortions and is uniformly densified. 
The Biot number can be estimated at the gear solid/gas internal and external interface from the temperature field using the method describe in Ref [31]. This number gives an indication of the relative importance of convection and conduction at the solid/gas interface. The Biot number is 1.5 and 0.035 on the sample internal and external solid/gas interface respectively. This difference indicates the heat transfer by convection is higher on the external solid/gas interface where the average gas velocity magnitude is about $5 \mathrm{E}-2 \mathrm{~m} / \mathrm{s}$ compare to the internal sample gas area where the gas velocity fall to $3 \mathrm{E}-4 \mathrm{~m} / \mathrm{s}$.
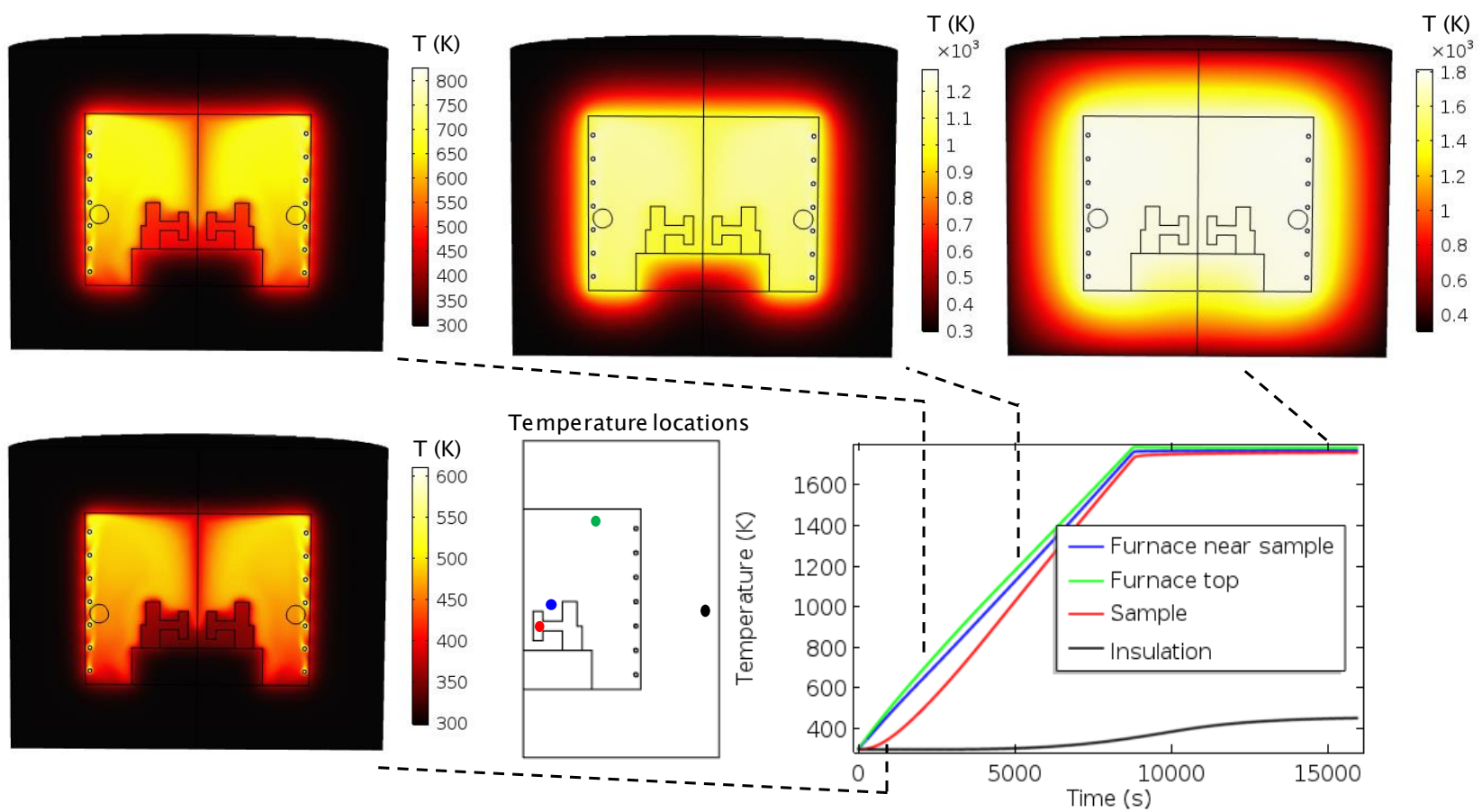

Fig.7 Temperature distribution for the gear configuration. 


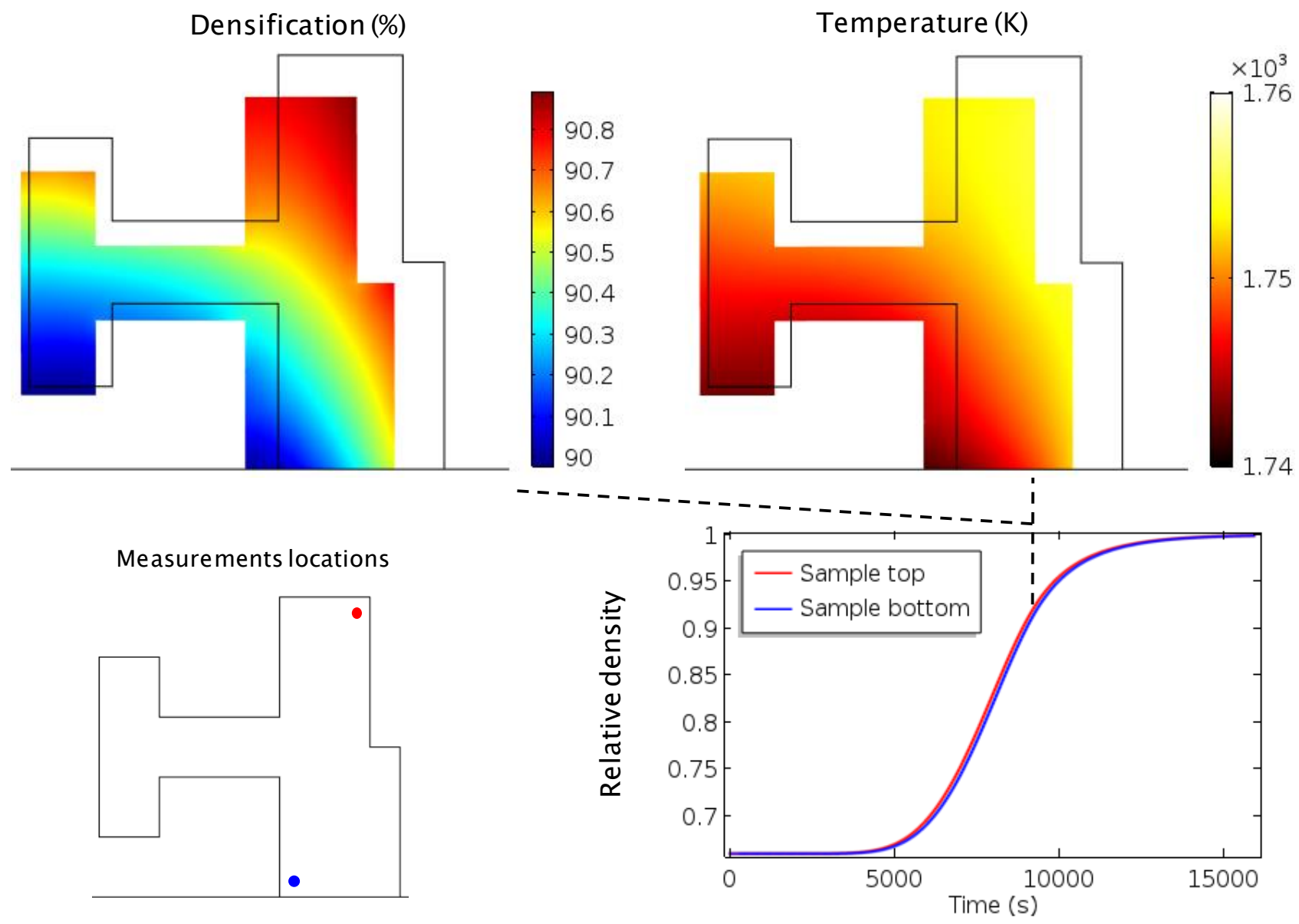

Fig. 8 Densification/temperature distribution for the gear sample configuration (the black line represents the initial sample geometry).

Similarly, the overall temperature distribution and sample relative density evolution are reported in fig.9 and fig.10 for the two-gear configuration, respectively. For this configuration, the first/second heating stage transition also happens between 2000-5000 s. During the first heating stage, the areas of heating lag are located in both gear/gas internal areas. The bottom gear gas area is colder than the one of the top gear because the gas penetrates this area through a very small $4 \mathrm{~mm}$ aperture on the edge. Despite this lag, the sample temperature during sintering is still homogeneous with temperature and densification differences of $20 \mathrm{~K}$ and $1 \%$ respectively. Similarly to the previously considered gear configuration, no sample shape distortions are observed. 


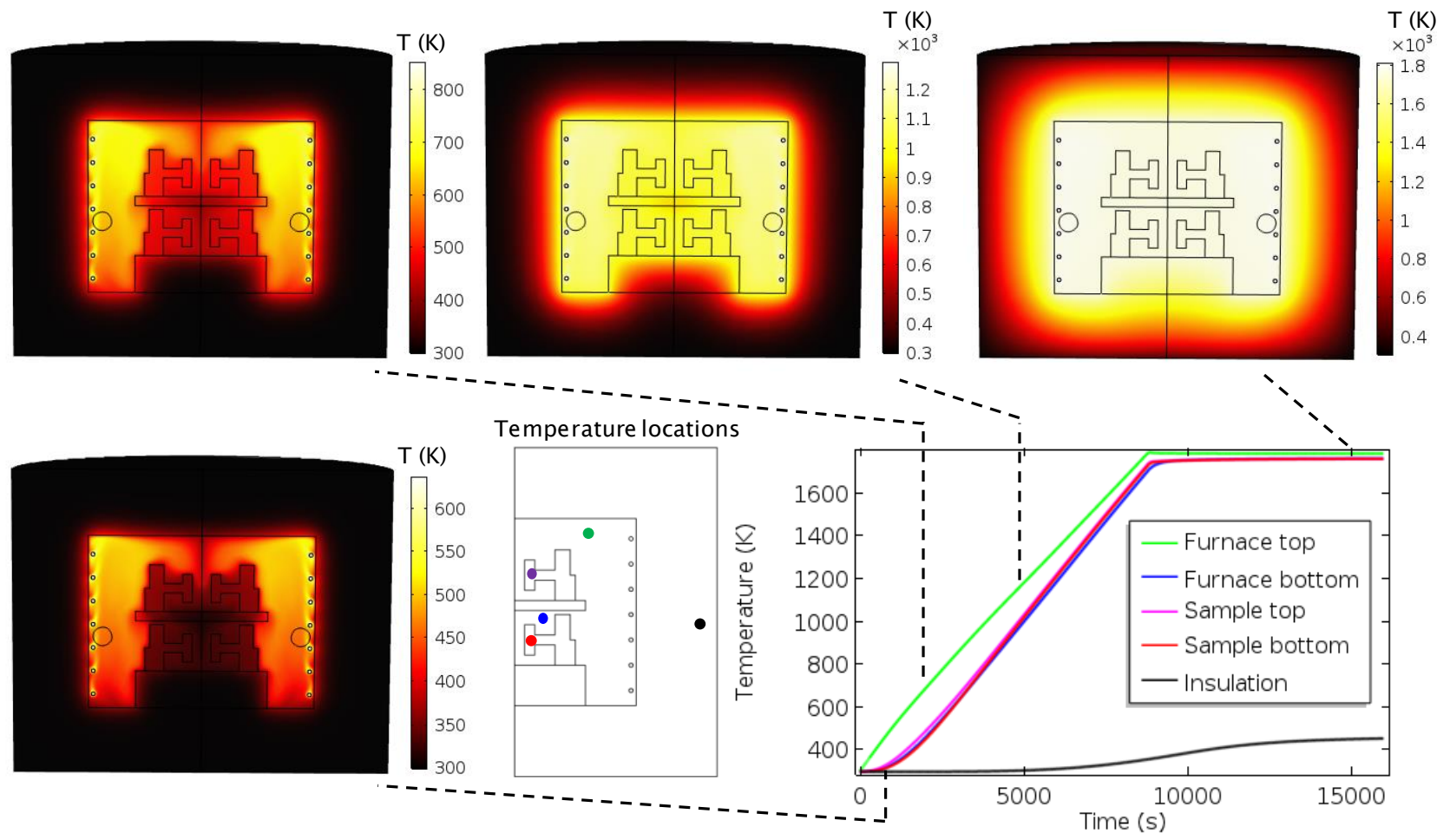

Fig.9 Temperature distribution for the two gear configuration. 

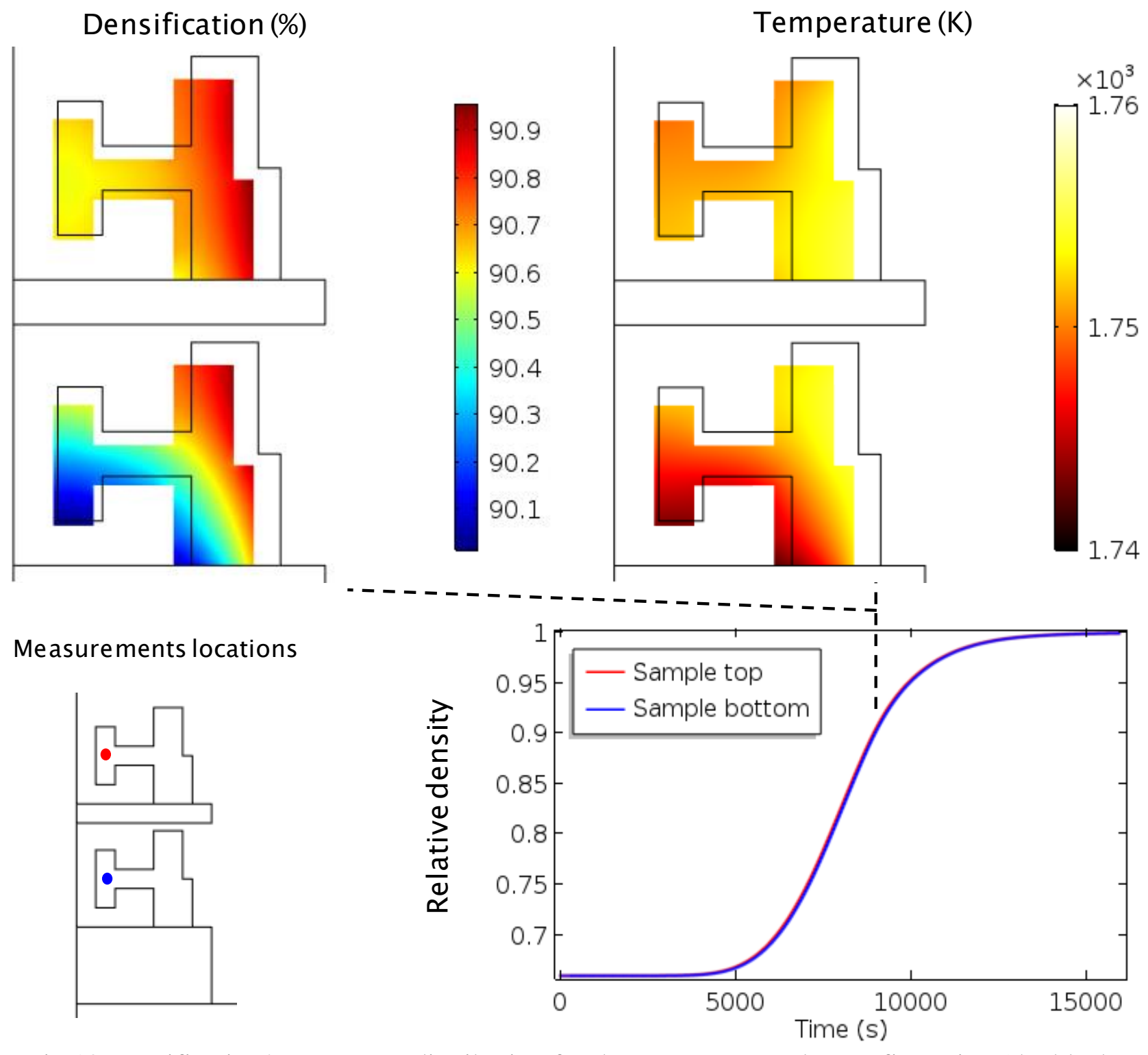

Measurements locations

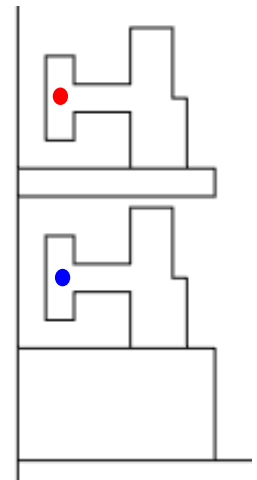

Fig.10 Densification/temperature distribution for the two gear samples configuration (the black lines represent the initial sample geometry).

For the both gear configurations (fig.7 and fig.9) the temperature in the main furnace gas area can be $200 \mathrm{~K}$ higher than in the sample during the heating ramp. This difference disappears during the holding time. Nevertheless, the physical fields in the sample are sufficiently homogeneous to allow sintering without distortions. In the next and last section, we determine which type of the analyzed configurations represents the real risk of the densification inhomogeneity. For this purpose, a large cylindrical volume of the powder material is tested. 


\subsection{Large closed volume heating}

In this configuration (fig. $2 \mathrm{~d}$ ) a large cylindrical (radius $=70 \mathrm{~mm}$ height $=70 \mathrm{~mm}$ ) closed volume of the powder material is tested. Similarly to the previous simulation, the overall furnace temperature distribution is reported in fig.11 and the sample temperature and densification are reported in fig.12. For the first time within the described calculation results, a significant temperature difference of about $70-100 \mathrm{~K}$ is observed (fig.11) between the sample center and the edge. This difference generates the temperature and the relative density gradients that can be seen in fig.12. At $8000 \mathrm{~s}$ the sample temperature difference is $70 \mathrm{~K}$ and the densification difference is $3.5 \%$. From the geometrical point of view, the cylindrical sample has the diameter closed to the overall gear diameter, therefore the main geometrical change (compared to the previously considered configurations) is the cylindrical sample shape that does not possess an aperture allowing the gas to penetrate in the center of the sample. Because of this difference the center of the sample is heated only by thermal conduction and the temperature difference increases from $20 \mathrm{~K}$ to $70 \mathrm{~K}$ and the densification from $1 \%$ to $3.5 \%$. The obtained results show that even if the gas motion in the gear sample area is very slow, it allows a small infiltration of heat in the sample central area which causes a more homogeneous heating for both gear shapes.

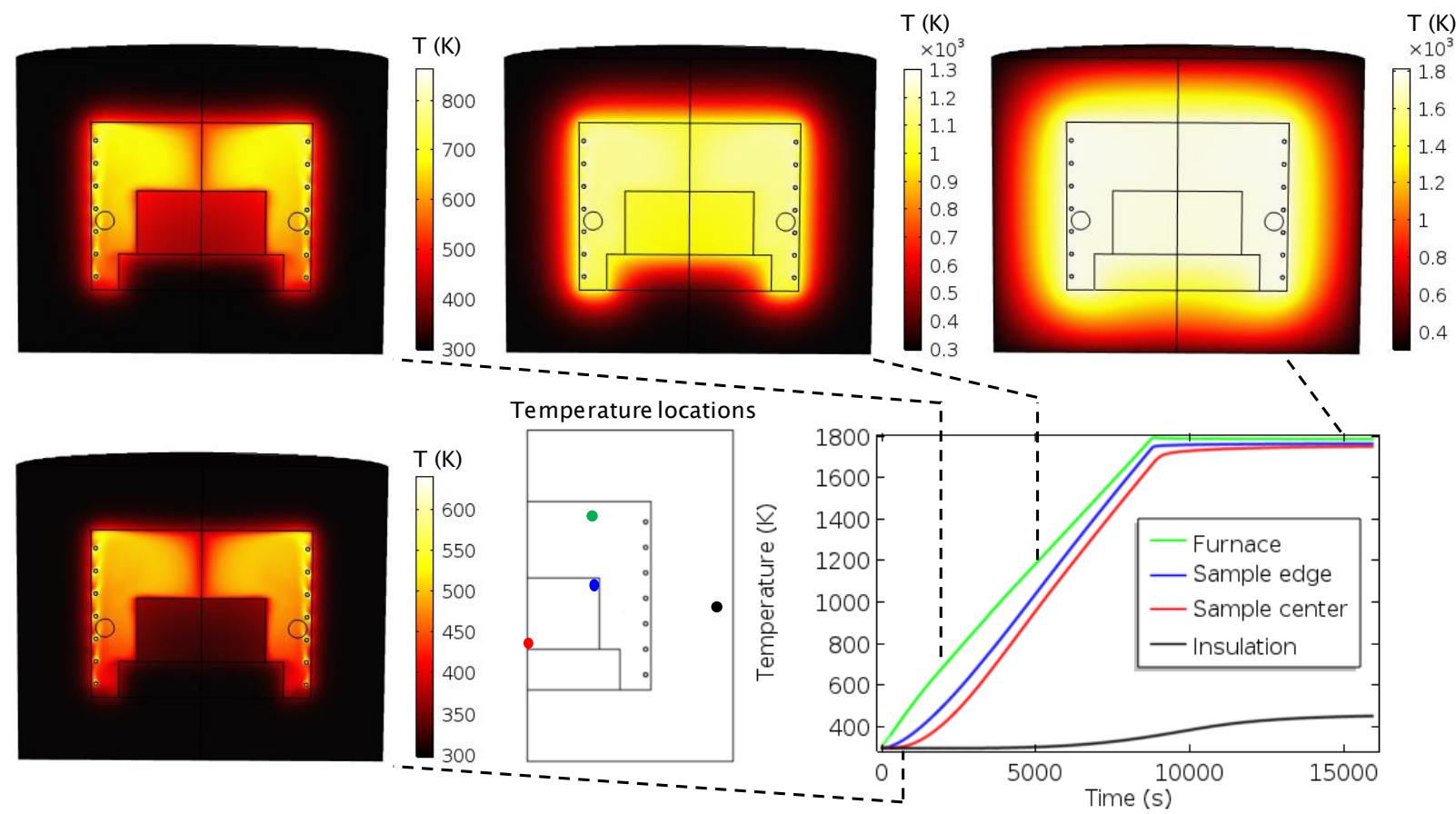

Fig.11 Temperature distribution for the large dimension cylinder configuration. 

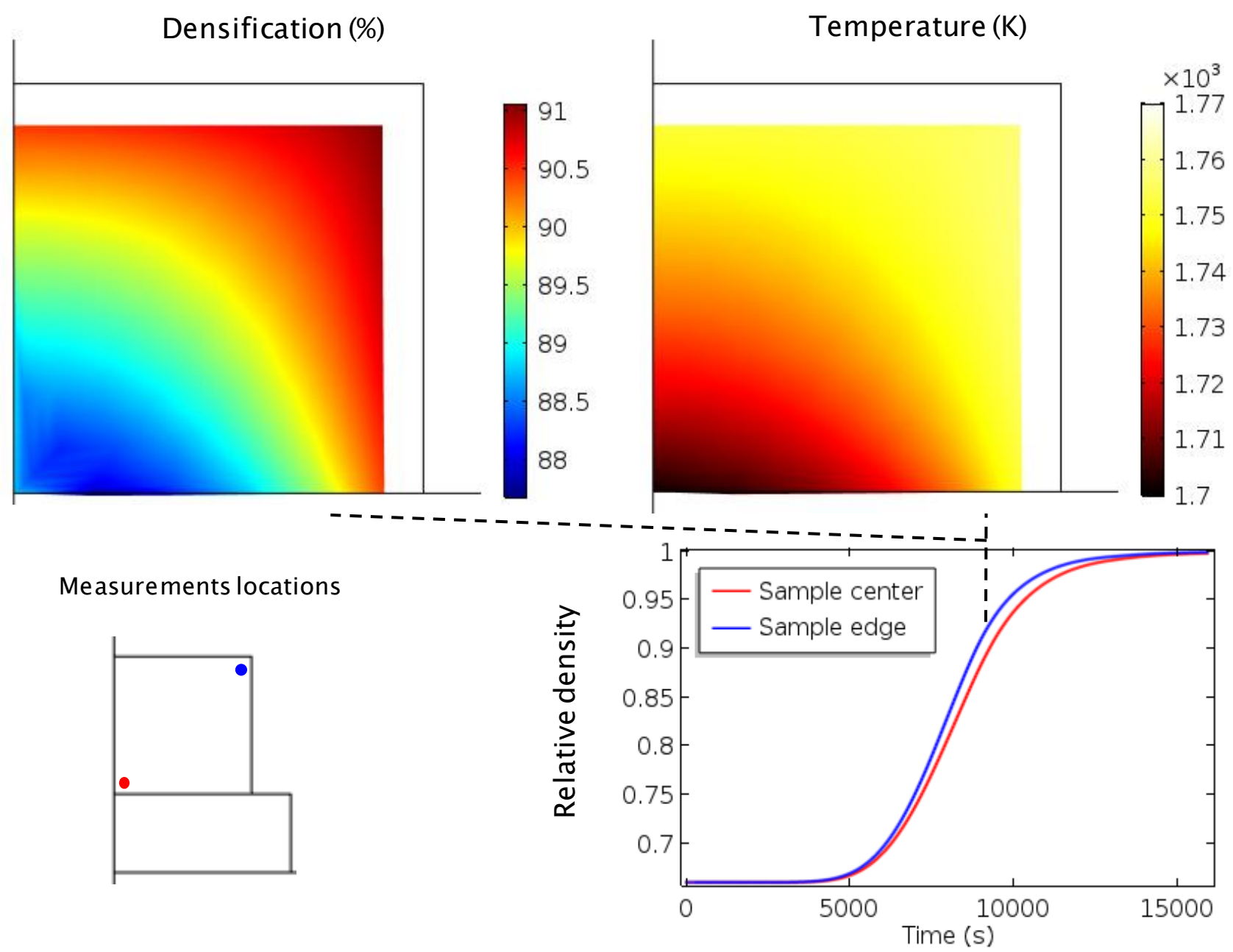

Fig.12 Densification/temperature distribution for the large dimension cylinder configuration (the black lines represent the initial sample geometry).

Beside the gas motion impact on the temperature and densification gradients, the scale effect can have a significant impact on the sintering of a green body. In order to understand the heating/densification homogeneity from small to very large scale, a parametric thermal-mechanical (TM) simulation study have been investigated and reported figure 13 . To prevent a very time consuming study, the simulations are investigated only on the sample with a surface imposed constant temperature. A $5 \mathrm{~K} / \mathrm{min}$ cycle is imposed up to a temperature of $1600 \mathrm{~K}$, the maximum and minimum temperature and densification differences are compared for a cylindrical sample whose size is homothetically increased from a radius of $10 \mathrm{~mm}$ to $1 \mathrm{~m}$. The simulated curves suggest a homogeneous heating and sintering for sample radius up to $150 \mathrm{~mm}$. A significant increase of the thermal/sintering inhomogeneity up to radius of about $400 \mathrm{~mm}$ for the densification and $700 \mathrm{~mm}$ for the temperatures is observed. After these respective radius, the densification and the heating became 
superficial and the sample center is neither heated nor sintered because the sample size in too large.

These heating/sintering behaviors can be improved for the large size by slower heating profiles. The use of both the FDTM and TM simulation tools are suited for complex shape and the scalability optimization studies of conventional sintering.

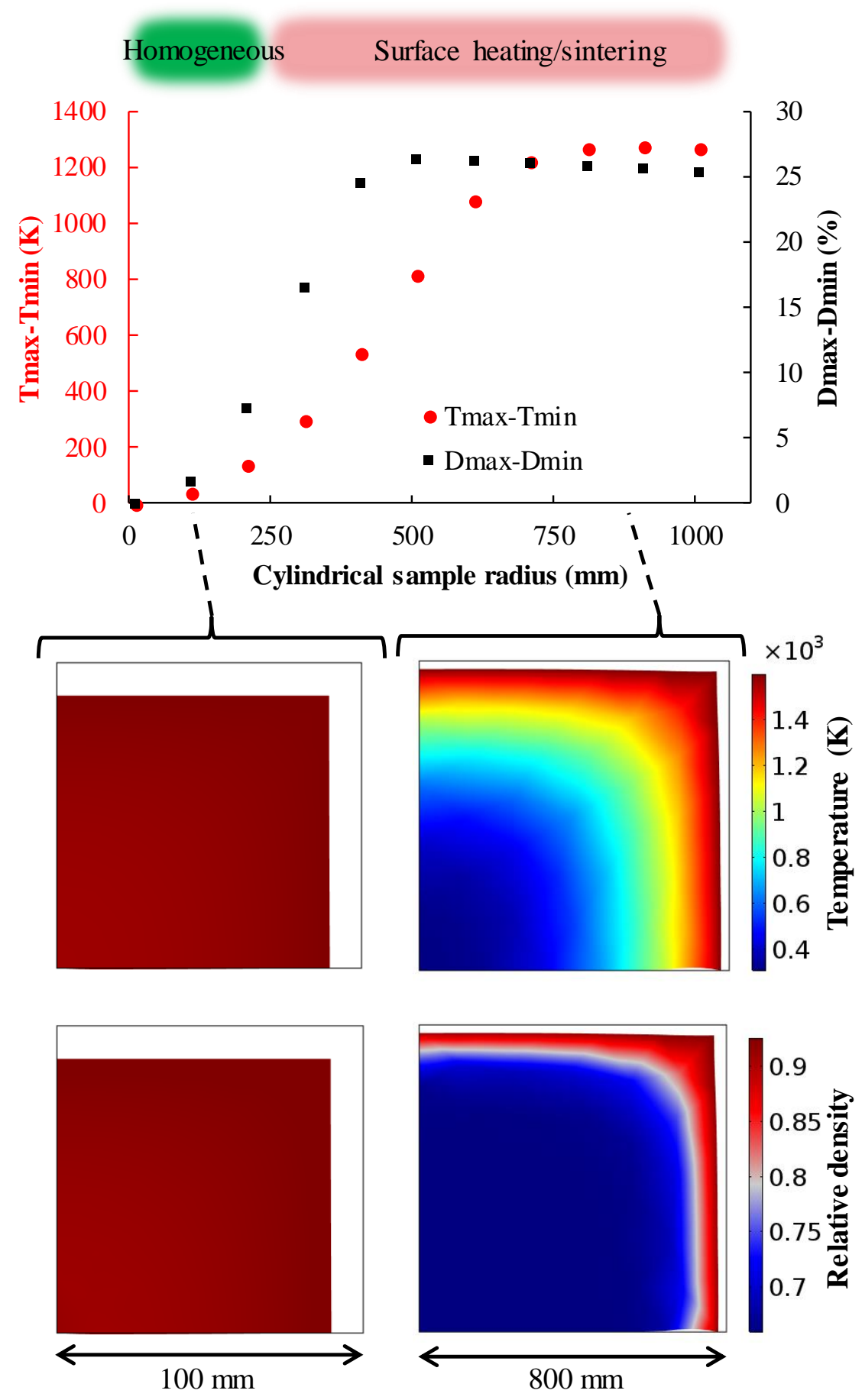

Fig.13 Scale effect on the temperature/relative density homogeneity; a cylindrical sample with same radius and height is surface heated for different size from $10 \mathrm{~mm}$ to $1 \mathrm{~m}$; the maximum and minimum temperatures and relative densities differences (Tmax-Tmin and Dmax-Dmin) are compared for each size. 


\section{Conclusions}

A fluid dynamics thermo-mechanical model able to predict the convection, radiation and the sintering phenomena involved in the conventional sintering process has been developed. This model has been successfully validated experimentally by a dilatometer test that allowed the comparison of the modeled and real temperature distribution and the sintering shrinkage of the sample. The simulations reveal a circular convection motion that quickly homogenizes the temperature in the furnace areas. When complex shapes or large dimension samples are used, the sample area is heated in lag. The gas areas present inside the complex shape samples are slowly heated in the initial stages of the heating due to the tortuosity of these areas. However, our study shows that these gas areas help homogenize the sample heating during sintering. Among those considered, the configuration that presents the most pronounced inhomogeneity is the cylindrical sample. This sample has a large closed volume that prevents the convection phenomena to increase the temperature of the central area that can be heated only by thermal conduction. The homogeneity of the heating of this type of the sample's shape depends on the duration of the heating and on the dimensions of the sample. The bigger is the sample dimensions, the slower the heating rate should be in order to ensure the homogeneity. The developed model is perfectly suited to determine the optimal sintering conditions for any sample configuration.

\section{Acknowledgments:}

The authors gratefully acknowledge the support from the Office of Naval Research, Contract \# N00014-14-C-0233, and Dr. William Mullins, Program Officer. 


\section{References:}

[1] R.M. German, History of Sintering, Sintering: From Empirical Observations to Scientific Principles. (2014) 13-40. doi:10.1016/b978-0-12-401682-8.00002-1.

[2] R.M. German, History of sintering: empirical phase, Powder Metallurgy. 56 (2013) 117-123. doi:10.1179/1743290112y.0000000025.

[3] E.A. Olevsky, Theory of sintering: from discrete to continuum, Materials Science and Engineering: R: Reports. 23 (1998) 41-100. doi:10.1016/s0927-796x(98)00009-6.

[4] V. N. Chougule, O. F. Daud, G. R. Gupta, V. H. Shelke, R. V. Ugale, Numerical Analysis of Combustion Furnace Performance by CFD, IOSR Journal of Mechanical and Civil Engineering, (2013) 72-79.

[5] http://www.azom.com/article.aspx?ArticleID=5772. (2017).

[6] V.N. Prokushin, A.A. Shubin, V.V. Kleimenov, V.V. Alekseev, E.N. Marmer, Carbon heating elements for high-temperature furnaces, Fibre Chemistry. 24 (1993) 503-504. doi:10.1007/bf00551614.

[7] A. Minea Adriana, A review on analytical techniques for natural convection investigation in a heated closed enclosure: Case study, Thermal Science. 19 (2015) 1077-1095. doi:10.2298/tsci131027021m..

[8] T.J.S. Brain, New thermal conductivity measurements for argon, nitrogen and steam, International Journal of Heat and Mass Transfer. 10 (1967) 737-744. doi:10.1016/00179310(67)90133-0.

[9] S.V. Egorov, K.I. Rybakov, V.E. Semenov, Y.V. Bykov, O.N. Kanygina, E.B. Kulumbaev, V.M. Lelevkin, Role of convective heat removal and electromagnetic field structure in the microwave heating of materials, Journal of Materials Science. 42 (2007) 2097-2104. doi:10.1007/s10853-006-0157-x.

[10] A. Minea Adriana, CFD Study on Heat Transfer in a Muffle Furnace, International Review of Mechanical Engineering. 3 (2009) 133.

[11] M.J. Sable, S. K. Bhor, S.B. Barve, P. A. Makasare, S. J. Jagtap, Computational Analysis for Enhancement of Natural Convection Heat Transfer on Vertical Heated Plate by Multiple V-Fin Array, International Journal of Applied Engineering Research. 6 (2011) 1617.

[12] J. Kang, Y. Rong, Modeling and simulation of load heating in heat treatment furnaces, Journal $\begin{array}{lllll}\text { of } & \text { Materials } & \text { Processing } & \text { 109-114. }\end{array}$ doi:10.1016/j.jmatprotec.2005.03.037.

[13] S.H. Han, D. Chang, C.Y. Kim, A numerical analysis of slab heating characteristics in a walking beam type reheating furnace, International Journal of Heat and Mass Transfer. 53 (2010) 3855-3861. doi:10.1016/j.ijheatmasstransfer.2010.05.002.

[14] R. Prieler, B. Mayr, M. Demuth, B. Holleis, C. Hochenauer, Prediction of the heating characteristic of billets in a walking hearth type reheating furnace using CFD, International Journal of Heat and Mass Transfer. 92 (2016) 675-688. doi:10.1016/j.ijheatmasstransfer.2015.08.056.

[15] A.A. Minea, Simulation of heat transfer processes in an unconventional furnace, Journal of Engineering Thermophysics. 19 (2010) 31-38. doi:10.1134/s1810232810010054.

[16] V. Ovchinnikov, Analysis of Furnace Operational Parameters for Controllable Annealing of Thin Films. ICQNM (2014) 32-37.

[17] A.O. Nieckele, M.F. Naccache, M.S.P. Gomes, Numerical Modeling of an Industrial Aluminum Melting Furnace, Journal of Energy Resources Technology. 126 (2004) 72. doi:10.1115/1.1625396.

[18] E. Hachem, G. Jannoun, J. Veysset, M. Henri, R. Pierrot, I. Poitrault, E. Massoni, T. Coupez, Modeling of heat transfer and turbulent flows inside industrial furnaces, Simulation Modelling Practice and Theory. 30 (2013) 35-53. doi:10.1016/j.simpat.2012.07.013. 
[19] E. Hachem, T. Kloczko, H. Digonnet, T. Coupez, Stabilized finite element solution to handle complex heat and fluid flows in industrial furnaces using the immersed volume method, International Journal for Numerical Methods in Fluids. 68 (2010) 99-121. doi:10.1002/fld.2498.

[20] E. Hachem, H. Digonnet, E. Massoni, T. Coupez, Immersed volume method for solving natural convection, conduction and radiation of a hat-shaped disk inside a 3D enclosure, International Journal of Numerical Methods for Heat \& Fluid Flow. 22 (2012) 718-741. doi:10.1108/09615531211244871.

[21] A. Minea Alina, A. Dima, Saving energy through improving convection in a muffle furnace, Thermal Science. 12 (2008) 121-125. doi:10.2298/tsci0803121m.

[22] C. Manière, T. Zahrah, E.A. Olevsky, Inherent heating instability of direct microwave sintering process: Sample analysis for porous 3Y-ZrO 2, Scripta Materialia. 128 (2017) 4952. doi:10.1016/j.scriptamat.2016.10.008.

[23] E.A. Olevsky, C. Garcia-Cardona, W.L. Bradbury, C.D. Haines, D.G. Martin, D. Kapoor, Fundamental Aspects of Spark Plasma Sintering: II. Finite Element Analysis of Scalability, Journal of the American Ceramic Society. 95 (2012) 2414-2422. doi:10.1111/j.15512916.2012.05096.x.

[24] V.V. Skorohod, Rheological basis of the theory of sintering, Naukova Dumka, Kiev, (1972).

[25] C. Manière, U. Kus, L. Durand, R. Mainguy, J. Huez, D. Delagnes, C. Estournès, Identification of the Norton-Green Compaction Model for the Prediction of the Ti-6Al-4V Densification During the Spark Plasma Sintering Process, Advanced Engineering Materials. 18 (2016) 1720-1727. doi:10.1002/adem.201600348.

[26] F. Li, J. Pan, Modelling "Nano-Effects" in Sintering, Sintering. (2012) 17-34. doi:10.1007/978-3-642-31009-6_2.

[27] C. Manière, T. Zahrah, E.A. Olevsky, Fully Coupled Electromagnetic-Thermal-Mechanical Comparative Simulation of Direct vs. Hybrid Microwave Sintering of 3Y-ZrO2, Accepted for publication in Journal of the American Ceramic Society. (2017).

[28] V.V. Yakovlev, S.M. Allan, M.L. Fall, H.S. Shulman, Computational Study of Thermal Runaway in Microwave Processing of Zirconia, Conference paper at AMPERE 2011, Toulouse. (2011).

[29] C. Manière, L. Durand, E. Brisson, H. Desplats, P. Carré, P. Rogeon, C. Estournès, Contact resistances in spark plasma sintering: From in-situ and ex-situ determinations to an extended model for the scale up of the process, Journal of the European Ceramic Society. 37 (2017) 1593-1605. doi:10.1016/j.jeurceramsoc.2016.12.010.

[30] www.matweb.com (2017).

[31] T.W. Davies, BIOT NUMBER, A-to-Z Guide to Thermodynamics, Heat and Mass Transfer, and Fluids Engineering. (n.d.). (2011) doi:10.1615/atoz.b.biot_number.

\section{Highlights:}

* A muffle furnace heat transfer analysis is combined with modeling of sintering.

Complex sample shape, flow tortuosity effects on the furnace sintering are revealed.

The densification homogeneity dependence on sintered sample dimensions is determined. 